\title{
A ANÁLISE DE TÉCNICAS DA MATEMÁTICA FINANCEIRA APLICADAS NA FIXAÇÃO DO QUANTUM DEBEATUR NAS LIDES QUE ENVOLVEM CÁLCULOS DE FINANCIAMENTO
}

André Junior Silva Wiezzel

Universidade do Oeste Paulista - UNOESTE. Curso de Ciências Contábeis. E-mail: andrejunior@unoeste.br

\section{RESUMO}

Este trabalho tem por escopo apresentar ao leitor alguns recursos oferecidos pela matemática financeira no sentido de dirimir questões judiciais envolvendo o recálculo do valor das parcelas de financiamento, onde se investiga a possível existência de juros abusivos no montante de cada parcela. Não se incumbe esse artigo em discutir questões de Direito, mas sim, debater as metodologias de cálculos que vêm sendo reiteradamente levados à apreciação do Poder Judiciário, eivados de vícios e contradições, onde tais valores pouco colaboram com a justiça onde se vê como única motivação a obtenção de vantagem financeira de um ou outro pólo litigante. Não obstante, o Perito Judicial Contador deverá apontar com convicção os valores devidos, embasado pelos recursos oferecidos pela matemática financeira para o deslinde da questão. No final deste artigo, o leitor terá a oportunidade de apreciar as variáveis quem envolvem a discussão e os caminhos apontados pela Perícia Judicial Contábil.

Palavras-chave: matemática financeira, perícia judicial contábil, valor devido, metodologia, cálculo.

\section{INTRODUÇÃO E JUSTIFICATIVA}

Tem sido prática recorrente por parte de alguns devedores a de ajuizar ações civis contra as instituições financeiras no sentido de discutir a (re) composição do valor das prestações contratadas.

Alinhada com a meta de praticar a justiça, vem a profissão do Perito Judicial Contador a representar um instrumento de grande valia para auxiliar o trabalho do Magistrado, vez que, tido como um Expert em cálculos, sinaliza ao Julgador onde, como e porque determinado valor condiz ou não com a verdade, já que em alguns casos, o emaranhado de números (e os argumentos apresentados pelas partes, por vezes recheados de dogmas) terminam por dificultar as decisões que envolvem a fixação de uma sentença, onde, por vezes, se faz necessário enxergar com "olhos de Caeiro". Também compartilha desta visão o autor MAGALHÃES (2008), que acentua o fato de ser o Magistrado um douto em direito, mas não o é em quaisquer assuntos.

Vivendo em uma sociedade capitalista, o homem tem em seu âmago o incessante interesse em acumular bens e riquezas, de sorte que, não raras vezes, o que realmente interessa não é o justo, e a retidão dá lugar ao oportunismo. Neste Norte, assistimos colegas de profissão que se intitulam como assessores e vendem ilusão ao seu cliente, onde o último, também ávido 
por interesses materialistas, não percebe a fragilidade de certos argumentos e deposita toda sua confiança em cálculos (milagrosos) que apontam para um endividamento (no caso da prestação aludida) um tanto inferior ao valor contratado, utilizando métodos que distorcem os ensinamentos trazidos pela matemática financeira.

Mas, onde e porque há tamanha contradição entre as partes envolvidas (devedor e credor) no tangente ao correto valor de cada prestação?

Por parte do credor, é comum a alegação de que o devedor ao assinar o contrato estava ciente de todas as condições, onde o contrato reza, invariavelmente, que incidirão juros compostos na transação (legalmente previstos). No que diz respeito ao devedor, esse reclama que há amparo legal no sentido de proibir a cobrança de juros capitalizados, conhecida como Anatocismo. Mas, caro leitor, atente para um aspecto fundamental nesse confronto: será que os juros compostos são sinônimos de prática do Anatocismo? Já adiantamos que o assunto é controvertido e até o momento não pacificado.

Eis aqui alguns pontos que envolvem a discussão judicial: se o Anatocismo é proibido por lei, na hipótese dos juros compostos serem considerados também como juros sobre os juros, então estaria o valor da prestação inchado por juros ilegais? Se há leis que amparam simultaneamente os dois pólos litigantes, haveria outra ferramenta de cálculo que pudessem apontar ao juiz um valor médio para a prestação, sem afrontar diretamente um ou outro pólo?

Em nome da ética profissional que resguarda o valor social da profissão do contador, $\mathrm{e}$ em função do nobre papel que este assume frente à situação exposta, nos parece razoável ponderar o grau de contribuição que este artigo poderá produzir, não no sentido de firmar único entendimento sobre a questão, mas despertar o desejo de ampliar as pesquisas e estudos no entorno da matemática financeira, direito e contabilidade, cujos ensinamentos, numa visão dialética, devem coexistir e direcionar para sanar as demandas desta natureza.

\section{METODOLOGIA}

Nesta etapa apresentaremos ao leitor o recurso matemático utilizado pela instituição financeira (credor) para fixar o valor da prestação, através do Sistema Price. Para o cálculo da prestação, será utilizada a seguinte formulação: $P M T=\left[\left(P \times / \times(1+l)^{n}\right) /(1+l)^{n}-1\right]$, onde $P M T$ é a prestação fixada, $P$ é o valor principal, $n$ é o período e $i$ é a taxa mensal de juros.

Separadamente, abordaremos também o modo procedimental comumente apresentado pelo devedor para o mesmo cálculo, conhecido como Método de Gauss. A comparação entre os 
dois cálculos permitirá ao leitor se questionar: se os dois métodos utilizados são extraídos de modelos matemáticos, porque há tamanha discrepância entre os valores de cada método? Vamos debater no subitem vindouro (na parte de discussão) o que poderia explicar a grande variação nos valores colhidos de cada método.

A prestação calculada por este método (Gauss) advém da aplicação da seguinte fórmula: $P M T=[P \times(I \times n)+P] /\{[I \times(n-1) / 2]+1\} \times n$, onde $P M T$ é a prestação fixada, $P$ é o valor principal, $n$ é o período e l é a taxa mensal de juros.

Finalizando, estaremos apresentando uma metodologia alternativa sugerida por dois autores brasileiros que pode representar uma conciliação de valores, com a aplicação de Logaritmo Natural $\left(L_{n}\right)$. Veremos que a metodologia deste cálculo leva em conta a formulação abaixo mencionada:

FEP $=[(2 \times I) / L N((1+n \times I) .(1+n \times I+I)) /(1+I)]$, tal que: PMT é o valor da prestação, $P$ o valor do principal, FEP é o fator estimado de parcelamento, $I$ é a taxa de juros (expressa em numeral), n é o total de períodos e $L N$ o logaritmo natural.

Resultados

Vamos simular uma situação que nos permitirá melhor compreender a discussão, sendo que esses dados hipotéticos serão utilizados em três perspectivas diferentes para fins de cálculo do valor da prestação.

Considere neste contexto que o contrato de financiamento tenha entabulado as seguintes condições: juros de 2,34\% ao mês, com pagamento em 48 meses, cujo valor financiado tenha sido de $\mathrm{R} \$ 15.052,67$ (quinze mil e cinqüenta e dois reais e sessenta e sete centavos).

a)Do valor da prestação fixada pelo banco:

Vamos compreender a fórmula utilizada pelo banco para a fixação da parcela, demonstrada pelos autores Lima e Nishiyama (2007, p. 141):

$P M T=\left[\left(P \times / \times(1+l)^{n}\right) /(1+l)^{n}-1\right]$, onde $P M T$ é a prestação fixada, $P$ é o valor principal, $n$ é o período e $i$ é a taxa mensal de juros.

$$
\begin{aligned}
& P M T=\left[\left(R \$ 15.052,67 \times 0,0234 \times(1+0,0234)^{48}\right) /(1+0,0234)^{48}-1\right] \\
& P M T=[(R \$ 15.052,67 \times 0,0234 \times 3,035148) / 3,035148-1] \\
& P M T=[R \$ 1.069,08 / 2,035148]=R \$ 525,31
\end{aligned}
$$

b) Do valor da prestação defendida pelo devedor: 
Com base no Método de Gauss, vem o devedor apresentar seu entendimento a respeito da fixação do valor da prestação. Neste sentido, $P M T$ é a prestação fixada, $P$ é o valor principal, $n$ é o período e $i$ é a taxa mensal de juros.

$$
\begin{aligned}
& P M T=P \times(i \times n)+P] /\{[i \times(n-1) / 2]+1\} \times n \\
& \mathrm{PMT}=[\mathrm{R} \$ 15.052,67 \times(0,0234 \times 48)+\mathrm{R} \$ 15.052,67] /\{[0,0234 \times(48-1) / 2]+1\} \times 48 \\
& \mathrm{PMT}=[\mathrm{R} \$ 15.052,67 \times 1,1232+\mathrm{R} \$ 15.052,67] /\{[0,0234 \times 47 / 2]+1\} \times 48 \\
& \\
& \mathrm{PMT}=\mathrm{R} \$ 31.959,83 /\{[0,0234 \times 23,50]+1\} \times 48 \\
& \mathrm{PMT}=\mathrm{R} \$ 31.959,83 /\{0,5499+1\} \times 48 \\
& \mathrm{PMT}=\mathrm{R} \$ 31.959,83 / 74,3952=\mathrm{R} \$ 429,60 \\
& \text { C) Do cálculo alternativo para a fixação do valor da prestação } \\
& \text { FEP }=[(2 \times I) / L N((1+n \times l) .(1+n \times I+l)) /(1+I)], \text { tal que: } P M T \text { é o valor da }
\end{aligned}
$$

prestação, $P$ o valor do principal, FEP é o fator estimado de parcelamento, $I$ é a taxa de juros (expressa em numeral), n é o total de períodos e $L N$ o logaritmo natural.

Nesta acepção, tem-se que o FEP será assim determinado:

$$
\begin{aligned}
& \text { FEP }=[(2 . i) / \operatorname{LN}((1+n . i) .(1+n . i+i)) /(1+i)] \\
& F E P=[0,0468 / \operatorname{LN}((2,1232 \times 2,1466) / 1,0234)] \\
& \text { FEP }=0,0468 / \operatorname{LN} 4,45345038 \\
& \text { FEP }=0,0468 / 1,49367916 \\
& \text { FEP }=0,03133203
\end{aligned}
$$

Por meio do FEP, calcula-se o valor da prestação:

$$
\begin{aligned}
& \mathrm{PMT}=\mathrm{FEP} \times \mathrm{P} \\
& \mathrm{PMT}=0,01332033 \times 15.052,07=\mathrm{R} \$ 471,61
\end{aligned}
$$

\section{DISCUSSÃO}

a)Do valor da prestação fixada pelo banco:

É bastante habitual a utilização do Sistema Francês de Amortização, também conhecido como Tabela Price, cuja funcionalidade se dá no sentido de apontar 0 valor da amortização da dívida, incorporando ao processo a utilização de juros compostos.

Vimos anteriormente que $P M T=\left[\left(P \times I \times(1+l)^{n}\right) /(1+l)^{n}-1\right]=R \$ 525,31 \mathrm{e}$, resta agora, compreender o efeito da capitalização contida na tabela Price. Para tal, é interessante proceder a uma breve análise sobre o conceito de Valor Presente (VP), onde o valor presente representa o valor no tempo atual de recursos que serão consumidos no 
futuro (pagamentos com as taxas de juros nele agregados). Tomemos um exemplo de quais seriam os valores presentes, isto é, o valor atual que representa os pagamentos futuros, vez que o valor definido para cada parcela $(R \$ 525,31)$ foi fixado por cálculo em exponencial (juros compostos):

Tabela 01: Demonstração da prática dos juros compostos na Tabela Price

\begin{tabular}{|c|c|c|c|c|c|c|c|}
\hline $\begin{array}{l}\text { № DE } \\
\text { PREST } \\
.\end{array}$ & $\begin{array}{c}\text { AMORTIZ. } \\
\text { DA } \\
\text { DÍVIDA }\end{array}$ & $\begin{array}{c}\text { JUROS } \\
\text { EMBUTIDO } \\
\text { S }\end{array}$ & $\begin{array}{c}\text { PRESTAÇÃ } \\
0 \\
\text { A PAGAR }\end{array}$ & $\begin{array}{c}\text { SALDO } \\
\text { DEVEDO } \\
\text { R }\end{array}$ & $\begin{array}{c}\text { VALOR DA } \\
\text { PRESTAÇÃ } \\
0\end{array}$ & $\begin{array}{l}\text { DIVISOR } \\
(1+\mathrm{i})^{\mathrm{n}}\end{array}$ & $\begin{array}{c}\text { PRESTAÇÃ } \\
0 \\
\text { (VP) }\end{array}$ \\
\hline \multicolumn{8}{|c|}{$\begin{array}{c}15.052,6 \\
7\end{array}$} \\
\hline 1 & 173,08 & 352,23 & 525,31 & $\begin{array}{c}14.879,5 \\
9\end{array}$ & 525,31 & $\begin{array}{c}1,0234000 \\
0 \\
\end{array}$ & 513,30 \\
\hline 2 & 177,13 & 348,18 & 525,31 & $\begin{array}{c}14.702,4 \\
6\end{array}$ & 525,31 & $\begin{array}{c}1,0473475 \\
6\end{array}$ & 501,56 \\
\hline 3 & 181,27 & 344,04 & 525,31 & $\begin{array}{c}14.521,1 \\
9\end{array}$ & 525,31 & $\begin{array}{c}1,0718554 \\
9\end{array}$ & 490,09 \\
\hline 4 & 185,51 & 339,80 & 525,31 & $\begin{array}{c}14.335,6 \\
8 \\
\end{array}$ & 525,31 & $\begin{array}{c}1,0969369 \\
1 \\
\end{array}$ & 478,89 \\
\hline 5 & 189,86 & 335,45 & 525,31 & $\begin{array}{c}14.145,8 \\
2 \\
\end{array}$ & 525,31 & $\begin{array}{c}1,1226052 \\
4 \\
\end{array}$ & 467,94 \\
\hline 6 & 194,30 & 331,01 & 525,31 & $\begin{array}{c}13.951,5 \\
3 \\
\end{array}$ & 525,31 & $\begin{array}{c}1,1488742 \\
0 \\
\end{array}$ & 457,24 \\
\hline 7 & 198,84 & 326,47 & 525,31 & $\begin{array}{c}13.752,6 \\
8\end{array}$ & 525,31 & $\begin{array}{c}1,1757578 \\
5\end{array}$ & 446,78 \\
\hline 8 & 203,50 & 321,81 & 525,31 & $\begin{array}{c}13.549,1 \\
8 \\
\end{array}$ & 525,31 & $\begin{array}{c}1,2032705 \\
9 \\
\end{array}$ & 436,57 \\
\hline 9 & 208,26 & 317,05 & 525,31 & $\begin{array}{c}13.340,9 \\
3\end{array}$ & 525,31 & $\begin{array}{c}1,2314271 \\
2 \\
\end{array}$ & 426,59 \\
\hline 10 & 213,13 & 312,18 & 525,31 & $\begin{array}{c}13.127,7 \\
9 \\
\end{array}$ & 525,31 & $\begin{array}{c}1,2602425 \\
1\end{array}$ & 416,83 \\
\hline 11 & 218,12 & 307,19 & 525,31 & $\begin{array}{c}12.909,6 \\
7\end{array}$ & 525,31 & $\begin{array}{c}1,2897321 \\
9\end{array}$ & 407,30 \\
\hline 12 & 223,22 & 302,09 & 525,31 & $\begin{array}{c}12.686,4 \\
5 \\
\end{array}$ & 525,31 & $\begin{array}{c}1,3199119 \\
2 \\
\end{array}$ & 397,99 \\
\hline 13 & 228,45 & 296,86 & 525,31 & $\begin{array}{c}12.458,0 \\
0\end{array}$ & 525,31 & $\begin{array}{c}1,3507978 \\
6\end{array}$ & 388,89 \\
\hline 14 & 233,79 & 291,52 & 525,31 & $\begin{array}{c}12.224,2 \\
1 \\
\end{array}$ & 525,31 & $\begin{array}{c}1,3824065 \\
3 \\
\end{array}$ & 380,00 \\
\hline 15 & 239,26 & 286,05 & 525,31 & $\begin{array}{c}11.984,9 \\
5\end{array}$ & 525,31 & $\begin{array}{c}1,4147548 \\
4\end{array}$ & 371,31 \\
\hline 16 & 244,86 & 280,45 & 525,31 & $\begin{array}{c}11.740,0 \\
8 \\
\end{array}$ & 525,31 & $\begin{array}{c}1,4478601 \\
1\end{array}$ & 362,82 \\
\hline 17 & 250,59 & 274,72 & 525,31 & $\begin{array}{c}11.489,4 \\
9\end{array}$ & 525,31 & $\begin{array}{c}1,4817400 \\
3 \\
\end{array}$ & 354,52 \\
\hline
\end{tabular}




\begin{tabular}{|c|c|c|c|c|c|c|c|}
\hline 18 & 256,46 & 268,85 & 525,31 & $\begin{array}{c}11.233,0 \\
4\end{array}$ & 525,31 & $\begin{array}{c}1,5164127 \\
5 \\
\end{array}$ & 346,42 \\
\hline 19 & 262,46 & 262,85 & 525,31 & $\begin{array}{c}10.970,5 \\
8 \\
\end{array}$ & 525,31 & $\begin{array}{c}1,5518968 \\
1 \\
\end{array}$ & 338,50 \\
\hline 20 & 268,60 & 256,71 & 525,31 & $\begin{array}{c}10.701,9 \\
8\end{array}$ & 525,31 & $\begin{array}{c}1,5882111 \\
9\end{array}$ & 330,76 \\
\hline 21 & 274,88 & 250,43 & 525,31 & $\begin{array}{c}10.427,1 \\
0\end{array}$ & 525,31 & $\begin{array}{c}1,6253753 \\
4\end{array}$ & 323,19 \\
\hline 22 & 281,32 & 243,99 & 525,31 & $\begin{array}{c}10.145,7 \\
8 \\
\end{array}$ & 525,31 & \begin{tabular}{|c|}
1,6634091 \\
2 \\
\end{tabular} & 315,80 \\
\hline 23 & 287,90 & 237,41 & 525,31 & $9.857,88$ & 525,31 & \begin{tabular}{|c|}
1,7023328 \\
9 \\
\end{tabular} & 308,58 \\
\hline 24 & 294,64 & 230,67 & 525,31 & $9.563,25$ & 525,31 & \begin{tabular}{|c|}
1,7421674 \\
8 \\
\end{tabular} & 301,53 \\
\hline 25 & 301,53 & 223,78 & 525,31 & $9.261,72$ & 525,31 & $\begin{array}{c}1,7829342 \\
0 \\
\end{array}$ & 294,63 \\
\hline 26 & 308,59 & 216,72 & 525,31 & $8.953,13$ & 525,31 & $\begin{array}{c}1,8246548 \\
6 \\
\end{array}$ & 287,90 \\
\hline 27 & 315,81 & 209,50 & 525,31 & $8.637,32$ & 525,31 & $\begin{array}{c}1,8673517 \\
9 \\
\end{array}$ & 281,31 \\
\hline 28 & 323,20 & 202,11 & 525,31 & $8.314,13$ & 525,31 & \begin{tabular}{|c|}
1,9110478 \\
2 \\
\end{tabular} & 274,88 \\
\hline 29 & 330,76 & 194,55 & 525,31 & $7.983,37$ & 525,31 & $\begin{array}{c}1,9557663 \\
4 \\
\end{array}$ & 268,60 \\
\hline 30 & 338,50 & 186,81 & 525,31 & $7.644,87$ & 525,31 & \begin{tabular}{|c|}
2,0015312 \\
7 \\
\end{tabular} & 262,45 \\
\hline 31 & 346,42 & 178,89 & 525,31 & $7.298,45$ & 525,31 & $\begin{array}{c}2,0483671 \\
0 \\
\end{array}$ & 256,45 \\
\hline 32 & 354,53 & 170,78 & 525,31 & $6.943,92$ & 525,31 & $\begin{array}{c}2,0962988 \\
9 \\
\end{array}$ & 250,59 \\
\hline 33 & 362,82 & 162,49 & 525,31 & $6.581,10$ & 525,31 & \begin{tabular}{|c|}
2,1453522 \\
8 \\
\end{tabular} & 244,86 \\
\hline 34 & 371,31 & 154,00 & 525,31 & $6.209,79$ & 525,31 & \begin{tabular}{|c|}
2,1955535 \\
3 \\
\end{tabular} & 239,26 \\
\hline 35 & 380,00 & 145,31 & 525,31 & $5.829,79$ & 525,31 & \begin{tabular}{|c|}
2,2469294 \\
8 \\
\end{tabular} & 233,79 \\
\hline 36 & 388,89 & 136,42 & 525,31 & $5.440,89$ & 525,31 & $\begin{array}{c}2,2995076 \\
3 \\
\end{array}$ & 228,44 \\
\hline 37 & 397,99 & 127,32 & 525,31 & $5.042,90$ & 525,31 & $\begin{array}{c}2,3533161 \\
1\end{array}$ & 223,22 \\
\hline 38 & 407,31 & 118,00 & 525,31 & $4.635,59$ & 525,31 & $\begin{array}{c}2,4083837 \\
1 \\
\end{array}$ & 218,12 \\
\hline 39 & 416,84 & 108,47 & 525,31 & $4.218,76$ & 525,31 & \begin{tabular}{|c}
2,4647398 \\
8 \\
\end{tabular} & 213,13 \\
\hline 40 & 426,59 & 98,72 & 525,31 & $3.792,17$ & 525,31 & $\begin{array}{c}2,5224148 \\
0 \\
\end{array}$ & 208,26 \\
\hline 41 & 436,57 & 88,74 & 525,31 & $3.355,59$ & 525,31 & 2,5814393 & 203,50 \\
\hline
\end{tabular}




\begin{tabular}{|l|l|l|l|l|} 
& & & & \\
\hline 42 & 446,79 & 78,52 & 525,31 & $2.908,80$ \\
\hline 43 & 457,24 & 68,07 & 525,31 & $2.451,56$ \\
\hline 44 & 467,94 & 57,37 & 525,31 & $1.983,62$ \\
\hline 45 & 478,89 & 46,42 & 525,31 & $1.504,72$ \\
\hline 46 & 490,10 & 35,21 & 525,31 & $1.014,62$ \\
\hline 47 & 501,57 & 23,74 & 525,31 & 513,06 \\
\hline 48 & 513,30 & 12,01 & 525,31 & $-0,25$ \\
\hline
\end{tabular}

\begin{tabular}{|c|c|c|}
\hline & 0 & \\
\hline 525,31 & $\begin{array}{c}2,6418449 \\
8\end{array}$ & 198,84 \\
\hline 525,31 & $\begin{array}{c}2,7036641 \\
6\end{array}$ & 194,30 \\
\hline 525,31 & $\begin{array}{c}2,7669299 \\
0 \\
\end{array}$ & 189,85 \\
\hline 525,31 & $\begin{array}{c}2,8316760 \\
6\end{array}$ & 185,51 \\
\hline 525,31 & $\begin{array}{c}2,8979372 \\
8 \\
\end{array}$ & 181,27 \\
\hline 525,31 & $\begin{array}{c}2,9657490 \\
1\end{array}$ & 177,13 \\
\hline 525,31 & $\begin{array}{c}3,0351475 \\
4\end{array}$ & 173,08 \\
\hline & & $15.052,75$ \\
\hline
\end{tabular}

Fonte: o autor

Conforme se vê, para cada valor presente corresponde um valor de amortização. Essa é mais uma demonstração de que os efeitos causados pela Tabela Price são exatamente os mesmos causados pelos juros compostos, uma vez que cada valor de amortização do principal de um contrato calculado pela Tabela Price, corresponderia a um contrato a ser calculado por juros compostos, onde se averigua uma sequência invertida de amortização. Observe-se que ao final das 48 parcelas, ter-se-á por meio do total da soma da coluna "Prestação (VP)" na tabela intitulada por "Valor Presente das Prestações" o valor financiado no início do contrato, tal seja, $R \$ 15.052,07$ (a tabela apresenta o valor de $\mathrm{R} \$ 15.052,75$ por questões de arredondamento de casas decimais).

b) Do valor da prestação defendida pelo devedor:

Com base no Método de Gauss, vem o devedor apresentar seu entendimento a respeito da fixação do valor da prestação, munido do argumento de que neste sistema de cálculo não há ocorrência de juros sobre juros, já que a formulação não se utiliza cálculos em exponencial. Contudo, Gauss não apresentou em seus trabalhos ferramentas aplicáveis à matemática financeira, carecendo o método de validade para aplicação neste caso específico.

c) Do cálculo alternativo para a fixação do valor da prestação

De acordo com ou autores Lima e Nishiyama (2007), trata-se de uma sugestão de cálculo para fixar o valor da parcela com vistas a eliminar o efeito dos juros compostos, respeitando também o valor do dinheiro no tempo. Pode-se ponderar que sua aplicação resulta em um valor moderado (ou seja, não cria uma tendência de valor para baixo ou para cima) e respeita os ensinamentos da matemática financeira. 


\section{CONCLUSÃO}

Sobre a utilização da tabela Price, $e$, consoante nosso entendimento, há incidência de juros compostos na Tabela Price, vez que as parcelas do pagamento calculadas em valor presente retornam exatamente no valor principal, reforçando o entendimento de que não há diferença entre o uso da aludida tabela e a prática de juros compostos.

No que concerne ao uso do Método de Gauss, discordamos também da validade desse método, uma vez que o matemático Gauss não se dedicou aos estudos de matemática financeira, tampouco a fornecer instrumentos para que a ela fossem aplicados. Gauss fez, entre diversos outros, estudos ligados à estatística e sobre probabilidades, sendo o Método de Gauss um estudo sobre a "distribuição normal" de erros estatísticos.

Finalizando, no que diz respeito ao método apresentado por Lima e Nishiyama (2007), em havendo dúvida sobre o que deveria ser praticado em nome da justiça, tenho que o método se revela adequado, vez que é um valor intermediário entre os interesses das partes (indicando neutralidade) e leva em conta o valor do dinheiro no tempo, ao mesmo tempo em que não utiliza fator exponencial em sua fórmula, afastando a incidência de juros compostos.

\section{REFERÊNCIAS}

LIMA, R. A. S. ; NISHIYAMA, A. M. Contratos bancários: aspectos jurídicos e técnicos da matemática financeira para advogados. São Paulo: Atlas, 2007.

MAGALHÃES, A. D. F.; LUNKES, I. C. Perícia Contábil nos Processos Cível e Trabalhista. São Paulo: Atlas, 2008. 